\title{
Accuracy of external cause-of-injury coding in VA polytrauma patient discharge records
}

\author{
Kathleen F. Carlson, MS, PhD; ${ }^{1-2 *}$ Sean M. Nugent, BA; ${ }^{1}$ Joseph Grill, MS; $^{1}$ Nina A. Sayer, PhD $^{1-2}$ \\ ${ }^{1}$ Center for Chronic Disease Outcomes Research, Department of Veterans Affairs Medical Center, Minneapolis, MN; \\ ${ }^{2}$ Department of Medicine, University of Minnesota Medical School, Minneapolis, MN
}

\begin{abstract}
Valid and efficient methods of identifying the etiology of treated injuries are critical for characterizing patient populations and developing prevention and rehabilitation strategies. We examined the accuracy of external cause-of-injury codes (E-codes) in Veterans Health Administration (VHA) administrative data for a population of injured patients. Chart notes and E-codes were extracted for 566 patients treated at any one of four VHA Polytrauma Rehabilitation Center sites between 2001 and 2006. Two expert coders, blinded to VHA E-codes, used chart notes to assign "gold standard" E-codes to injured patients. The accuracy of VHA E-coding was examined based on these gold standard E-codes. Only 382 of 517 (74\%) injured patients were assigned E-codes in VHA records. Sensitivity of VHA E-codes varied significantly by site (range: 59\%-91\%, $p<0.001$ ). Sensitivity was highest for combat-related injuries (81\%) and lowest for fall-related injuries (60\%). Overall specificity of E-codes was high (92\%). E-coding accuracy was markedly higher when we restricted analyses to records that had been assigned VHA E-codes. E-codes may not be valid for ascertaining source-of-injury data for all injuries among VHA rehabilitation inpatients at this time. Enhanced training and policies may ensure more widespread, standardized use and accuracy of E-codes for injured veterans treated in the VHA.
\end{abstract}

Key words: administrative data, causes of injury, E-codes, hospital discharge records, ICD codes, injury surveillance, medical records, missing data, rehabilitation, veterans.

\section{INTRODUCTION}

Traumatic injuries are the leading cause of hospitalization among Active Duty military personnel [1]. Injuries are also a leading diagnosis among veterans of Operation Iraqi Freedom/Operation Enduring Freedom (OIF/OEF) seeking care in the Veterans Health Administration (VHA) healthcare system [2]. Interestingly, studies have shown that veterans who have been deployed are at greater risk of fatal injuries following deployment than veterans from the same military service era who were not deployed [3-4]. Since the beginning of OIF/OEF, the VHA has been treating an increasing number of veterans

\footnotetext{
Abbreviations: $\mathrm{CI}=$ confidence interval, $\mathrm{E}$-code $=$ external cause-of-injury code, GS = gold standard, HSR\&D = Health Services Research and Development, ICD-9-CM = International Classification of Diseases-9th Revision-Clinical Modification, ICD-10-CM = ICD-10th Revision-Clinical Modification, OIF/ $\mathrm{OEF}=$ Operation Iraqi Freedom/Operation Enduring Freedom, PRC = Polytrauma Rehabilitation Center, TBI = traumatic brain injury, VA = Department of Veterans Affairs, VHA = Veterans Health Administration.

*Address all correspondence to Kathleen F. Carlson, MS, PhD; Portland Center for the Study of Chronic, Comorbid Mental and Physical Disorders, Portland VA Medical Center, 3710 SW US Veterans Hospital Rd, Portland, OR 97239. Email: kathleen.carlson@va.gov

DOI:10.1682/JRRD.2009.08.0118
} 
with traumatic injuries incurred during or after their military service. To meet the needs of these patients, the VHA created the Polytrauma System of Care, which includes 4 regional Polytrauma Rehabilitation Centers (PRCs) that provide inpatient care, 22 Polytrauma Network Sites that specialize in outpatient rehabilitation programs, multidisciplinary polytrauma teams at smaller VHA facilities, and designated points of contact at all other VHA facilities [5]. Most patients treated in the PRCs have sustained a traumatic brain injury (TBI) in combination with other injuries that have led to significant impairments [6-7]. To date, there has been no systematic study of the etiology of these patients' injuries, such as the proportion related to different forms of combat or the proportion related to postdeployment motor vehicle crashes. As Scott et al. and Belanger et al. have argued, such information has implications for clinical service delivery [8-9]. For example, knowledge of injury mechanism can prompt systematic screenings for sequelae or comorbidities commonly associated with the particular source of injury. Knowledge of injury etiology is also critical for development of postdeployment injury prevention efforts.

Details on the etiology of injuries treated within VHA can be collected through a comprehensive review of an individual patient's chart notes. This process requires access to the Computerized Patient Record System, the VHA's electronic medical record system, and is laborious if not time-prohibitive for understanding injury trends in large patient populations. An alternative, more efficient approach to collecting information on injuries treated in the VHA is the use of administrative data. The International Classification of Diseases-9th Revision-Clinical Modification (ICD-9-CM) coding manual includes a supplemental set of codes called "E-codes" (short for "external cause-of-injury codes") that are specific to traumatic injury [10] and are included in VHA administrative data. E-codes (codes E800.0-E999.9) were developed for injury surveillance [11] and are to be assigned whenever one or more ICD-9-CM injury diagnosis code (codes 800.00-999.9) is applied to a patient record [12-13]. Additionally, E-codes should be assigned to any other condition outside this range that is due to an external cause [12].

While diagnosis codes provide information on the anatomical nature of injuries (type and body region[s] involved), E-codes provide details on the source (e.g., blast/explosion, motor vehicle, fall), intent (unintentional, self-inflicted, assault), and circumstances (e.g., handgun vs rifle, driver vs passenger) of injury events. Additional E-codes indicate place of occurrence (e.g., home, public building) of the injury. The source and intent of injury are usually captured by the first three digits of an E-code. However, similar to diagnosis codes, E-codes can be up to five digits in length, with the fourth and fifth digits identifying the more specific circumstances of an injury event. For example, E991 represents an injury due to war operations by bullets and fragments, while E991.3 specifies that the fragments were due to an antipersonnel bomb. Also similar to diagnosis codes, "late effects" E-codes exist for identifying medical encounters relevant to the late effects or sequelae of an injury and are to be used whenever a late effects diagnosis code is assigned. For example, a veteran seeking treatment for postconcussive symptoms due to a blast-related TBI experienced in theater might be assigned a late effects diagnosis code of 907.0 ("late effect of intracranial injury without skull fracture”) along with a late effects E-code of E999.0 ("late effect of injury due to war operations"). Multiple E-codes may be assigned when more than one distinct source of injury is noted or when multiple E-codes are necessary to describe complete details of a single source of injury. For example, an injury scenario in which an explosive device detonated underneath a vehicle would potentially be assigned E-codes from both the war operations and motor vehicle categories. A coding hierarchy exists such that certain injury sources (abuse, terrorism, cataclysmic events, and transport [i.e., motor vehicle] events) are prioritized and are to be coded first. We refer the reader to the Centers for Disease Control and Prevention Official Guidelines, available online, for further information on these and additional coding rules [12].

Medical records technicians with specialty training (typically a 2-year degree and certification) assign codes to VHA inpatient medical records within 14 days after patient discharge. The VHA maintains both rigorous qualification standards for medical records technicians and a comprehensive system of data validation for coding completeness and accuracy [14]. To our knowledge, no published scientific studies have examined the accuracy of E-coding within VHA, although one 2005 report stated that pilot studies were underway [15]. Rates of E-coding of injury-related hospitalization discharges in community hospitals vary across state systems and range from just over half to nearly 100 percent [16-17]. Studies examining the compliance and accuracy of E-coding in U.S. hospital discharge data [17-21] and emergency department electronic data [21-23] 
have shown wide variation in practices, with some systems providing relatively complete and accurate E-codes when compared with patient chart notes as the gold standard (GS) [20]. If E-coding for VHA patients were shown to be accurate, these data could be used to efficiently identify and enumerate mechanisms, intent, and circumstances of injuries being treated in the VHA system of care. The purpose of this study was to conduct a preliminary examination of E-coding practice and accuracy with use of a population of PRC inpatients.

\section{METHODS}

\section{Overview}

This study was based on data for 566 patients consecutively treated at any one of the four VHA PRC sites between October 2001 and January 2006. Data for PRC patients were extracted from Vista (Veterans Health Information System and Technology Architecture) and included patient characteristics, chart notes, principal diagnosis code, and additional ICD-9-CM diagnosis and E-codes entered into 1 of 13 available fields. This was a secondary analysis of data collected as part of a study to characterize the injuries and impairments of PRC patients wounded in combat [24].

While most veterans and servicemembers treated at the PRCs have sustained traumatic injuries, a small minority of patients are admitted to the PRCs after a stroke or other neurological condition. Similar to other E-code studies $[17,20,23,25]$, our approach was to identify patients who were treated for injuries and assign E-codes to these patients based on expert review of their medical records. We then assessed VHA E-coding accuracy based on the results of this review. Also consistent with other E-code studies, our focus was on selecting the single most appropriate source-of-injury E-code for each injury event, rather than selecting multiple E-codes, such as those identifying places of occurrence.

\section{Gold Standard E-coding}

Using the process followed by VHA coders, we conducted a detailed review of patients' History \& Physical and Discharge Summary chart notes to identify PRC patients who were treated for externally caused injuries and to establish GS E-codes for those stays. Our GS team of coders was blinded to E-codes assigned by VHA coders during this process. The team included the principal inves- tigator, who is an injury epidemiologist with experience in E-coding, and a certified medical records coder contracted through an external agency for purposes of this study. Each team member independently assigned E-codes to each appropriate record by using standards from the ICD-9-CM codebook [10] and coding guidelines [12], as well as VHA coding guidelines [13]. E-codes were then cross-validated for each record, with nonmatches (52\%) being reconciled through discussion and consensus. Almost all GS nonmatches were at the third through fifth digits, representing the more specific details of injury events.

\section{Measures}

Administrative data were used for analysis of patient demographic characteristics, while GS E-codes were used to summarize sources of patients' injuries. Because the focus of this study was on the potential utility of E-codes for identifying etiology of patients' injuries (rather than more specific circumstances of injury events), we collapsed E-codes into broad source-of-injury categories representing major sections of the E-code system. These categories were motor vehicles (E810.0-E825.9, E929.0-E929.1, E988.5); falls (E833.0-E835.9, E843.x, E880.0-E888.9, E929.3); assaults, including self-inflicted injuries (E950.0-E969.9); combat, including blasts/explosions and incidents related to “friendly fire” (E921.8, E922.3, E923.8, E979.2, E985.4, E990.0-999.1); and other (all other E-codes). Respective late effects E-codes were included in each category. In cases where more than one source of injury was E-coded by GS $(n=3)$ or VHA $(n=43)$ coders, we considered the record a match if either injury source was the same.

\section{Analyses}

We conducted descriptive analyses to characterize the study population and injury characteristics. VHA Ecoding accuracy was examined at two levels. First, we examined accuracy in E-coding practice (i.e., whether records had VHA E-codes when patients had externally caused injuries or, conversely, whether records did not have VHA E-codes when patients did not have externally caused injuries). Second, for records determined by GS coders to be related to externally caused injuries, we examined accuracy in source-of-injury E-coding within the collapsed categories. Because VHA E-coding was incomplete, we also examined accuracy of assigned Ecodes by restricting analyses to the injured patients who had been assigned an E-code by VHA coders. 
We estimated accuracy by computing the following statistics: (1) concordance, a measure of the overall accuracy in detecting the presence or absence of a condition (e.g., presence/absence of an externally caused injury, presence/absence of a specified source of injury); (2) sensitivity, a measure of the accuracy of detecting the presence of a condition; and (3) specificity, a measure of the accuracy of detecting the absence of a condition. We computed 95 percent confidence intervals (CIs) for each measure by using generalized estimating equations to more accurately reflect any variation due to the correlation of outcomes within PRC sites and, consequently, to safeguard against misleadingly narrow CIs by not accounting for such variation [26]. Accuracy was examined by PRC site, year of patient admission, and source-of-injury category.

\section{RESULTS}

\section{Patient and Injury Characteristics}

A summary of patient and injury characteristics is presented in Table 1. Of the 566 patients treated at a VHA PRC during the study time period, the majority ( $n=517$; 91\%) received treatment for externally caused injuries or their late effects/sequelae. Patients without externally caused injuries received treatment primarily for stroke, meningitis, or cardiac arrest leading to acquired brain injury. Of the 517 injured patients, 54 percent had sustained motor vehicle-related injuries while another 28 percent sustained injuries due to combat. A substantial proportion of patients ( $n=183$; 35\%) were injured during OIF/OEF deployments. The most frequent sources of deployment-related injuries were combat operations such as blasts/explosions (79\%) followed by motor vehicles (15\%). Of the remaining patients with injuries not related to OIF/OEF deployments ( $n=334$; $65 \%$ ), the most frequent sources of injuries were motor vehicles (74\%), falls (9\%), and assaults (8\%).

\section{E-coding Practice}

Statistics estimating accuracy in VHA E-coding practice are presented in Table 2. Overall concordance between GS and VHA coders was 75 percent. Among the 517 patients who were treated for externally caused injuries, only 382 had been assigned E-codes by VHA coders (VHA E-codes); thus, the sensitivity of VHA E-codes to detect injury-related discharges in these data was 74 percent. There was a wide and statistically significant variation in
Table 1.

Characteristics of patients admitted to VHA Polytrauma Rehabilitation Centers (PRCs).

\begin{tabular}{|c|c|c|}
\hline Characteristic & $\begin{array}{l}\text { Admitted for } \\
\text { Externally } \\
\text { Caused Injuries } \\
\quad(n=517)\end{array}$ & $\begin{array}{c}\text { Admitted for } \\
\text { Other Reasons } \\
\quad(n=49)\end{array}$ \\
\hline \multicolumn{3}{|l|}{ Sex, $n(\%)$} \\
\hline Male & $492(95.2)$ & $40(81.6)$ \\
\hline Female & $25(4.8)$ & $9(18.4)$ \\
\hline \multicolumn{3}{|l|}{ Age (yr), $n(\%)$} \\
\hline$<25$ & $288(55.7)$ & $14(28.6)$ \\
\hline $25-34$ & $147(28.4)$ & $12(24.5)$ \\
\hline $35-44$ & $67(13.0)$ & $17(34.7)$ \\
\hline 45-64 & $15(2.9)$ & $6(12.2)$ \\
\hline \multicolumn{3}{|l|}{ Location at Time of Event, $n$ (\%) } \\
\hline Continental United States & $283(54.7)$ & $31(63.3)$ \\
\hline OIF/OEF Deployment & $183(35.4)$ & $9(18.4)$ \\
\hline $\begin{array}{l}\text { Outside Continental United } \\
\text { States, Excluding OIF/OEF }\end{array}$ & $42(8.1)$ & $7(14.3)$ \\
\hline Unknown/Not Active Duty & $9(1.7)$ & $2(4.0)$ \\
\hline \multicolumn{3}{|l|}{ PRC Site, $n(\%)$} \\
\hline 1 & 105 (20.3) & $5(10.2)$ \\
\hline 2 & $110(21.3)$ & $6(12.2)$ \\
\hline 3 & 147 (28.4) & $24(49.0)$ \\
\hline 4 & $155(30.0)$ & $14(28.6)$ \\
\hline \multicolumn{3}{|l|}{ Date of PRC Admission, $n(\%)$} \\
\hline 2001-2004 & 304 (58.8) & $28(57.1)$ \\
\hline 2005-2006 & $213(41.2)$ & 21 (42.9) \\
\hline \multicolumn{3}{|l|}{ Sources of Injury, $n(\%)$} \\
\hline Motor Vehicles & $278(53.5)$ & - \\
\hline Combat & 145 (27.9) & - \\
\hline Falls & $35(6.7)$ & - \\
\hline Assaults/Self-Inflicted & $27(5.2)$ & - \\
\hline Other & $35(6.7)$ & - \\
\hline
\end{tabular}

${ }^{*}$ Total $N=520$, because 3 patients had two causes each.

OIF/OEF = Operation Iraqi Freedom/Operation Enduring Freedom, VHA = Veterans Health Administration.

Table 2.

Accuracy of VHA E-coding practice for 566 Polytrauma Rehabilitation Center (PRC) patients by PRC site.

\begin{tabular}{|c|c|c|c|}
\hline $\begin{array}{l}\text { PRC } \\
\text { Site }\end{array}$ & $\begin{array}{c}\text { Concordance } \\
\left(95 \% \mathrm{CI}^{*}\right)\end{array}$ & $\begin{array}{l}\text { Sensitivity } \\
\left(95 \% \text { CI }^{*}\right)\end{array}$ & $\begin{array}{l}\text { Specificity } \\
\left(95 \% \text { CI* }^{*}\right)\end{array}$ \\
\hline$\overline{\text { All }}$ & $75.4(63.6-84.4)$ & $73.9(61.1-83.6)$ & $91.8(83.2-96.2)$ \\
\hline 1 & 75.5 (66.6-82.6) & 74.3 (65.1-81.7) & $100(60.7-100)$ \\
\hline 2 & $60.3(51.2-68.8)$ & 59.1 (49.7-67.9) & 83.3 (36.9-97.7) \\
\hline 3 & 90.6 (85.3-94.2) & $91.2(85.4-94.8)$ & 87.5 (67.6-95.9) \\
\hline 4 & $70.4(63.1-76.8)$ & $67.7(60.0-74.6)$ & 100 (81.9-100) \\
\hline$p$-Value & $<0.001$ & $<0.001$ & 0.24 \\
\hline
\end{tabular}


sensitivity of VHA E-codes across facilities $(p<0.001)$. For example, VHA coders at Site 2 assigned E-codes to only 59 percent of those treated for injuries, while at Site 3, coders assigned E-codes to 91 percent of patients treated for injuries. Among the 49 PRC patients who were not treated for externally caused injuries, only 4 had been assigned E-codes by VHA coders, resulting in a high specificity of 92 percent. These VHA E-codes had been incorrectly assigned to patients who, for example, experienced cardiac arrest after overexertion (e.g., during training) or who fell subsequent to a cardiac event but did not receive treatment for a fall-related injury.

\section{Source-of-Injury E-coding}

Overall concordance between GS and VHA coders in determining which discharge records should be E-coded and in assigning the same source-of-injury category was 70 percent (95\% CI: 60\%-79\%; data not shown). Concordance varied significantly across sites (range: $57 \%-84 \%$; $p<$ 0.001). There was indication of improvement in E-coding accuracy over time, though this finding was not statistically significant $(p=0.096)$. Compared with data from 2001 through 2004 (concordance: 65\%; 95\% CI: 51\%-77\%), a 20 percent increase in concordance existed between GS and VHA E-codes in data from 2005 to 2006 (78\%; 95\% CI: 65\%-87\%). E-code accuracy also markedly improved when analyses were restricted to the 382 injured patients for whom VHA coders had assigned an E-code. Concordance between GS and VHA coders in assigning an E-code from the same source-of-injury category to these discharge records was 91 percent (95\% CI: 90\%-93\%); concordance was uniform across sites (range: $90 \%-93 \% ; p=0.73$ ).

Levels of sensitivity of VHA E-codes in detecting injuries associated with motor vehicles, falls, assaults, and combat are presented in Table 3. Across all sites combined, the sensitivity to detect specific sources of injury was highest for injuries related to combat (81\%). Sensitivity was uniformly lower for injuries associated with falls (60\%), motor vehicles (66\%), and assaults (67\%). Sensitivity to detect motor vehicle-related injuries varied significantly across sites, ranging from 55 percent at Site 2 to 87 percent at Site $3(p<0.001)$. When these analyses were restricted to include only the injured patients for whom VHA coders had assigned E-codes, sensitivity increased significantly ( $p<0.001$ for all categories; data not shown). Across all sites combined, VHA E-codes could detect injuries related to combat with a sensitivity of 95 percent (95\% CI: $90 \%-$ 98\%); falls, 88 percent (95\% CI: 87\%-88\%); motor vehicles, 92 percent (95\% CI: 90\%-94\%); and assaults, 95 percent (95\% CI: 92\%-97\%).

\section{DISCUSSION}

Although preliminary, these results indicate that E-codes may not be a valid source of injury etiology data for VHA rehabilitation inpatients at this time. We found E-codes to be missing for approximately one-fourth of polytrauma inpatients treated for injury. We also found evidence of systematic misclassification based on source of injury. If E-codes alone had been used to ascertain sourceof-injury information for this patient population, the proportion of injuries associated with combat would be overestimated, while the proportions due to falls, motor vehicles, and assaults would be underestimated. However, deficiencies in E-coding accuracy were related more to missing E-codes than to selection of incorrect E-codes, at least when examined by broad source-of-injury categories.

Table 3.

Sensitivity of VHA source-of-injury E-codes among 517 Polytrauma Rehabilitation Center (PRC) patients treated for externally caused injuries.

\begin{tabular}{|c|c|c|c|c|}
\hline \multirow{3}{*}{ PRC Site } & \multicolumn{4}{|c|}{ Source-of-Injury Category } \\
\hline & Motor Vehicles & Falls & Assaults/Self-Inflicted & Combat \\
\hline & Sensitivity (95\% CI*) & Sensitivity (95\% CI*) & Sensitivity (95\% CI*) & Sensitivity $\left(95 \% \mathrm{CI}^{*}\right)$ \\
\hline$\overline{\text { All }}$ & $65.8(52.4-77.1)$ & $60.0(40.1-77.1)$ & $66.7(55.4-76.3)$ & $81.4(71.5-88.4)$ \\
\hline 1 & $62.3(48.6-74.2)$ & $75.0(23.8-96.6)$ & 80.0 (30.9-97.8) & $77.1(60.5-88.1)$ \\
\hline 2 & $55.4(42.3-67.7)$ & $36.4(14.3-66.1)$ & $71.4(32.7-92.8)$ & 66.7 (47.3-81.7) \\
\hline 3 & $86.8(77.2-92.8)$ & 81.8 (49.3-95.4) & 72.7 (41.4-91.0) & $92.1(78.2-97.4)$ \\
\hline 4 & $57.0(46.8-66.6)$ & $55.6(25.1-82.3)$ & $25.0(3.4-76.2)$ & $84.4(70.8-92.4)$ \\
\hline$p$-Value & $<0.001$ & 0.14 & 0.39 & 0.057 \\
\hline
\end{tabular}

${ }^{*}$ Adjusted for correlation within PRC sites.

$\mathrm{CI}=$ confidence interval, E-codes = external cause-of-injury codes, VHA = Veterans Health Administration. 
The rate of E-coding in this study population (74\%) is lower than the average rates observed in national inpatient datasets. Coben et al. found that 86 percent of injury records in the Healthcare Cost and Utilization Project National Inpatient Sample were E-coded, while 87 percent across Statewide Inpatient Databases were E-coded [17]. Notable variation in E-code completeness has been observed across individual state systems (50\%-100\%) [16-17]. This variance has been associated with the presence and enforcement of state mandates for E-code collection as well as with the design of the discharge data system in which diagnosis and E-codes are entered (e.g., number of available coding fields and presence of fields dedicated for E-codes) [17]. We observed significant variation in Ecoding accuracy across the PRC facilities, which are located in four different states. However, patterns of variation were not consistent with the patterns observed in the same states in previous studies. For example, Site 2, which had the lowest rate of E-coding, is located in a state that had nearly perfect rates of E-coding in state hospital discharge data [16]. That patterns would not be consistent between different healthcare systems located in the same states suggests that E-coding awareness has less to do with training required for medical records coding certification and more to do with site policies and practices.

Incomplete E-coding can be due to several factors. Missing E-codes could result from insufficient injuryrelated details in patients' medical records. Previous research has found that medical records with fewer details were least likely to be E-coded and that coders believed better clinical documentation would improve E-coding rates [18,27-28]. In this patient population, we found sufficient information in most medical records to assign at least a nonspecific E-code capturing the broad source of injury (e.g., E819.x: motor vehicle traffic accident of unspecified nature). Therefore, lack of documentation is not a likely reason for the deficiencies in E-coding we observed.

A more likely reason for the observed incomplete Ecoding involves systems issues, such as insufficiencies in the electronic system in which VHA coders enter diagnosis and E-codes. Coders have only 13 fields in which they can enter ICD-9-CM diagnosis codes other than the principal diagnosis code. E-codes must also be entered in these fields. It was not unusual for these polytrauma patients to be assigned numerous diagnosis codes reflecting their traumatic injuries and related comorbidities. Diagnosis codes take precedence over supplemental E-codes because they are linked to reimbursement [29]. Future research involv- ing VHA medical records technicians and examining reasons for incomplete E-coding would be informative for quality improvement efforts. To date, research has endorsed training and incorporation of supplemental data fields specific to E-codes as methods of improving completeness [16-17]. The VHA should consider these mechanisms to enhance E-coding accuracy. Our findings suggest that some sites might need more attention than others.

We observed E-codes to be relatively accurate for identifying broad source-of-injury categories when VHA coders had assigned E-codes. We also found that VHA coders were more likely to assign E-codes correctly to injuries related to combat than to injuries related to other sources. Past studies have noted similar variation in Ecoding accuracy by injury etiology $[18,20,25]$. In the VHA setting, this finding might reflect heightened awareness of combat-related injuries, given the political context in which these cases are occurring and receiving treatment. Note, however, that the majority (54\%) of PRC patients were treated for injuries associated with motor vehicles, most of which occurred postdeployment. The Department of Veterans Affairs (VA) has recently shown increased interest in studying motor vehicle crashes among veterans [30]. Emphasis throughout the VHA on the preventability and gravity of all injuries, particularly those related to motor vehicles, might eventually lead to improved E-coding of injuries incurred outside of combat operations.

The VHA has been involved in initiatives to improve coding for combat-related injuries and, specifically, coding related to TBI [31]. Considerable interest exists in tracking long-term outcomes in veterans who sustained blast-related TBI [32]. While it is unclear in the ICD-9-CM coding guidelines at what point symptoms due to an injury should be considered "sequelae/late effects," a late effects E-code appeared appropriate for a number of polytrauma inpatients. We note that the details pertaining to injury sources and circumstances are lost when late effects E-codes are assigned. For example, only one late effects E-code exists for use with all injuries that are due to war operations (E999.0). Thus, distinguishing blastrelated injuries from other combat-related injuries is not possible when late effects E-codes are used.

The VHA will transition from the ICD-9-CM to the ICD-10th Revision-Clinical Modification (ICD-10-CM) system of coding by 2013 [33]. The ICD-10-CM contains substantially more codes than the ICD-9-CM, including E-codes [34]. E-codes are also built into the main coding 
structure of the ICD-10-CM rather than appearing as a separate, supplemental series of codes [34-35]. The VHA's transition to the ICD-10-CM and any related dissemination and training efforts provide a good window of opportunity to enhance E-coding awareness, standardization, and accuracy. Research-based knowledge of systematic coding inaccuracies could be used to guide these efforts.

\section{LIMITATIONS}

This study has several limitations. First, we collapsed E-codes across broad source-of-injury categories. This approach has been followed in other E-codes studies $[18,20,23]$ but overestimates accuracy of E-coding. Additionally, in cases where multiple E-codes had been assigned by either GS or VHA coders, we declared a match if either of the GS or VHA E-codes were the same. Therefore, our results pertaining to source-of-injury Ecoding likely overestimated the accuracy of E-codes in detecting injury sources. Further work should be conducted to examine precision across categories in greater detail. Second, E-codes assigned by the study team for research purposes may not have been a perfect GS by which to compare VHA E-codes. However, we considered this a reasonable approach, given that our team included a certified medical records coder, had E-coding expertise, focused solely on assigning E-codes, had ample time per record to review and select the most appropriate codes, and cross-validated selected codes through discussion and consensus. Finally, practice and accuracy of Ecoding for the population of rehabilitation inpatients we analyzed may not represent E-coding across a wider VHA inpatient population. Our study should serve as a basis for further, more comprehensive E-coding research on the universe of VHA inpatients treated for injury.

\section{CONCLUSIONS}

In addition to polytrauma, the VHA treats eligible veterans with a broad range of injuries incurred during and after military service. The systematic collection of data on injuries treated within VHA, including their causes, mechanisms, and circumstances, would benefit epidemiologic, health services, and rehabilitation research. Injury research is crucial not only for enhancement of clinical services offered to injured veterans but also for development of pre- vention strategies that are both appropriate and effective. E-codes may not be a valid source of data for injury surveillance at this time. However, with enhanced training and policies relevant to E-coding, the VHA could potentially ensure more widespread, standardized use and accuracy of E-codes.

\section{ACKNOWLEDGMENTS}

\section{Author Contributions:}

Study concept and design: K. F. Carlson, S. M. Nugent, J. Grill, N. A. Sayer. Acquisition of data: K. F. Carlson, S. M. Nugent, N. A. Sayer. Analysis and interpretation of data: K. F. Carlson, S. M. Nugent, J. Grill, N. A. Sayer.

Manuscript preparation: K. F. Carlson.

Critical revision of manuscript for important intellectual content: S. M. Nugent, J. Grill, N. A, Sayer.

Statistical analysis: J. Grill.

Financial Disclosures: The authors have declared that no competing interests exist.

Funding/Support: This material was based on work supported by research and training grants from VA Health Services Research and Development (HSR\&D) Service (grants RRP 06-150, TPP 67-005, and CDA 08-025), a locally-initiated project grant from the VA HSR\&D Service Center for Chronic Disease Outcomes Research (LIP 67-032), and support from the HSR\&D Service Polytrauma and BlastRelated Injuries Quality Enhancement Research Initiative.

Additional Contributions: We acknowledge the veterans of OIF/OEF and their families for their service to our country. The opinions expressed in this study do not necessarily represent those of the VA. Dr. Carlson is now with the Portland Center for the Study of Chronic, Comorbid Mental and Physical Disorders, Portland VA Medical Center. Institutional Review: The Minneapolis VA Medical Center Subcommittee on Human Studies reviewed and approved this research.

\section{REFERENCES}

1. Jones BH, Perrotta DM, Canham-Chervak ML, Nee MA, Brundage JF. Injuries in the military: A review and commentary focused on prevention. Am J Prev Med. 2000; 18(3 Suppl):71-84. [PMID: 10736543] DOI:10.1016/S0749-3797(99)00169-5

2. Batten SV. VA update on psychological health and TBI clinical initiatives [Internet]. Washington (DC): Department of Veterans Affairs; 2008 [updated 2008 Nov; cited 2009 Aug 10]. Available from: http://www.usuhs.mil/ussw/confpres/ presentations/DCoEBattenAMSUSUSSWPanel11Nov.ppt/.

3. Macfarlane GJ, Hotopf M, Maconochie N, Blatchley N, Richards A, Lunt M. Long-term mortality amongst Gulf War Veterans: Is there a relationship with experiences during 
deployment and subsequent morbidity? Int J Epidemiol. 2005;34(6):1403-8. [PMID: 16251257]

DOI:10.1093/ije/dyi205

4. Bell NS, Amoroso PJ, Wegman DH, Senier L. Proposed explanations for excess injury among veterans of the Persian Gulf War and a call for greater attention from policymakers and researchers. Inj Prev. 2001;7(1):4-9. [PMID: 11289533] DOI:10.1136/ip.7.1.4

5. Sigford BJ. "To care for him who shall have borne the battle and for his widow and his orphan" (Abraham Lincoln): The Department of Veterans Affairs polytrauma system of care. Arch Phys Med Rehabil. 2008;89(1):160-62.

[PMID: 18164348$]$ DOI:10.1016/j.apmr.2007.09.015

6. Lew HL, Poole JH, Vanderploeg RD, Goodrich GL, Dekelboum S, Guillory SB, Sigford B, Cifu DX. Program development and defining characteristics of returning military in a VA Polytrauma Network Site. J Rehabil Res Dev. 2007; 44(7):1027-34. [PMID: 18075959]

DOI:10.1682/JRRD.2007.05.0073

7. Lew HL. Rehabilitation needs of an increasing population of patients: Traumatic brain injury, polytrauma, and blastrelated injuries. J Rehabil Res Dev. 2005;42(4):xiii-xvi.

[PMID: 16320135]

DOI:10.1682/JRRD.2005.01.0124

8. Scott SG, Belanger HG, Vanderploeg RD, Massengale J, Scholten J. Mechanism-of-injury approach to evaluating patients with blast-related polytrauma. J Am Osteopath Assoc. 2006;106(5):265-70. [PMID: 16717367]

9. Belanger HG, Scott SG, Scholten J, Curtiss G, Vanderploeg RD. Utility of mechanism-of-injury-based assessment and treatment: Blast Injury Program case illustration. J Rehabil Res Dev. 2005;42(4):403-12. [PMID: 16320137] DOI:10.1682/JRRD.2004.08.0095

10. U.S. Department of Health and Human Services. International classification of diseases, 9th revision, clinical modifications (ICD-9-CM). 6th ed. DHHS Publication No. (PHS) 96-1260. Washington (DC): U.S. DHHS, Public Health Service, Health Care Financing Administration; 2006.

11. Sniezek JE, Finklea JF, Graitcer PL. Injury coding and hospital discharge data. JAMA. 1989;262(16):2270-72.

[PMID: 2795809]

DOI:10.1001/jama.262.16.2270

12. Official ICD-9-CM guidelines for coding and reporting [Internet]. April, 2005. Hyattsville (MD): U.S. DHHS National Center for Health Statistics; 2005 [updated 2005 Apr 1; cited 2009 Jul 24]. Available from:

http://www.cdc.gov/nchs/data/icd9/icdguide.pdf/.

13. Handbook for coding guidelines, version 6.0 [Internet]. Washington (DC): Department of Veterans Affairs Health Information Management; 2006 [updated 2006 Mar; cited 2009 Jul 24]. Available from:
http://vaww.virec.research.va.gov/References/Links/ HANDBOOK FOR CODING GUIDELINES V6-0.pdf./

14. Veterans Health Administration. Health information management clinical coding program procedures [Internet]. Washington (DC): Veterans Health Administration; 2007 Nov 2 [cited 2009 Dec 27]. Available from: http://www1.va.gov/vhapublications/ViewPublication.asp?pub ID=1614/.

15. Campbell RR, Bradham DD, Sanchez-Anguiano A, Werner DH, Spehar AM, French D, Palacios P. Developing a Veterans Health Administration (VHA) serious injury surveillance system that includes adverse event hospitalizations. In: Henriksen K, Battles JB, Lewin DI, Marks E, editors. Advances in patient safety from research to implementation, Vol 1. Rockville (MD): Agency for Healthcare Research and Quality; 2005. p. 259-73.

16. Abellera J, Conn JM, Annest JL, Kohn M. How states are collecting and using cause of injury data: 2004 update to the 1997 report. Atlanta (GA): Council of State and Territorial Epidemiologists; 2005.

17. Coben JH, Steiner CA, Barrett M, Merrill CT, Adamson D. Completeness of cause of injury coding in healthcare administrative databases in the United States, 2001. Inj Prev. 2006; 12(3):199-201. [PMID: 16751453$]$

DOI:10.1136/ip.2005.010512

18. Langlois JA, Buechner JS, O’Connor EA, Nacar EQ, Smith GS. Improving the $\mathrm{E}$ coding of hospitalizations for injury: Do hospital records contain adequate documentation? Am J Public Health. 1995;85(9):1261-65. [PMID: 7661235] DOI:10.2105/AJPH.85.9.1261

19. Lawrence BA, Miller TR, Weiss HB, Spicer RS. Issues in using state hospital discharge data in injury control research and surveillance. Accid Anal Prev. 2007;39(2):319-25.

[PMID: 17026946] DOI:10.1016/j.aap.2006.08.001

20. LeMier M, Cummings P, West TA. Accuracy of external cause of injury codes reported in Washington State hospital discharge records. Inj Prev. 2001;7(4):334-38.

[PMID: 11770664]

DOI:10.1136/ip.7.4.334

21. Wadman MC, Muelleman RL, Coto JA, Kellermann AL. The pyramid of injury: Using ecodes to accurately describe the burden of injury. Ann Emerg Med. 2003;42(4):468-78. [PMID: 14520317] DOI:10.1067/S0196-0644(03)00489-X

22. Schwartz RJ, Nightingale BS, Boisoneau D, Jacobs LM. Accuracy of e-codes assigned to emergency department records. Acad Emerg Med. 1995;2(7):615-20.

[PMID: 8521208]

DOI:10.1111/j.1553-2712.1995.tb03599.x

23. Hunt PR, Hackman H, Berenholz G, McKeown L, Davis L, Ozonoff V. Completeness and accuracy of International Classification of Disease (ICD) external cause of injury codes in 
emergency department electronic data. Inj Prev. 2007(13): 422-25. [PMID: 18056321]

DOI:10.1136/ip.2007.015859

24. Sayer NA, Chiros CE, Sigford B, Scott S, Clothier B, Pickett T, Lew HL. Characteristics and rehabilitation outcomes among patients with blast and other injuries sustained during the Global War on Terror. Arch Phys Med Rehabil. 2008; 89(1):163-70. [PMID: 18164349]

DOI:10.1016/j.apmr.2007.05.025

25. Langley J, Stephenson S, Thorpe C, Davie G. Accuracy of injury coding under ICD-9 for New Zealand public hospital discharges. Inj Prev. 2006;12(1):58-61. [PMID: 16461421] DOI:10.1136/ip.2005.010173

26. Liang KY, Zeger SL. Longitudinal data analysis using generalized linear models. Biometrika. 1986;73(1):13-22.

DOI:10.1093/biomet/73.1.13

27. McKenzie K, Enraght-Moony E, Harding L, Walker S, Waller G, Chen L. Coding external causes of injuries: Problems and solutions. Accid Anal Prev. 2008;40(2):714-18. [PMID: 18329425] DOI:10.1016/j.aap.2007.09.008

28. McKenzie K, Harding LF, Walker SM, Harrison JE, Enraght-Moony EL, Waller GS. The quality of cause-ofinjury data: Where hospital records fall down. Aust N Z J Public Health. 2006;30(6):509-13. [PMID: 17209264$]$ DOI:10.1111/j.1467-842X.2006.tb00777.X

29. Rice DP, MacKenzie EJ; Centers for Disease Control (U.S.); United States National Highway Traffic Safety Administration; Johns Hopkins University Injury Prevention Center; University of California, San Francisco Institute for Health \& Aging. Cost of injury in the United States: A report to Congress, 1989. San Francisco (CA): Institute for Health \& Aging, University of California, and Injury Prevention Center, The Johns Hopkins University; San Francisco; 1989.

30. Veterans' safe driving initiative: Home safe, drive safe, stay safe [Internet]. Washington (DC): Department of Veterans Affairs; 2008 [updated 2008 Dec; cited 2009
Aug 10]. Available from: http://www.safedriving.va.gov/ docs/safe driving brochure.pdf/.

31. Fact sheet: Interim coding guidance for traumatic brain injury. Washington (DC): VHA Health Information Management, Office of Health Data and Informatics; 2008.

32. Gulf War and health: Volume 7. Long-term consequences of traumatic brain injury [Internet]. Washington (DC): Institute of Medicine; 2008 [updated 2010 Jan 4; cited 2009 Aug 10]. Available from: http://www.iom.edu/Reports/2008/GulfWar-and-Health-Volume-7-Long-term-Consequences-ofTraumatic-Brain-Injury.aspx/.

33. HIPAA administrative simplification: Modifications to medical data code set standards to adopt ICD-10-CM and ICD-10PCS. Washington (DC): Department of Health and Human Services; 2008.

34. Katcher ML, Agran P, Laraque D, Pollack SH, Smith GA, Spivak HR, Tenenbein M, Tully SB. The hospital record of the injured child and the need for external cause-of-injury codes. American Academy of Pediatrics. Committee on Injury and Poison Prevention, 1998-1999. Pediatrics. 1999; 103(2):524-26. [PMID: 9925858]

35. Langley JD, Chalmers DJ. Coding the circumstances of injury: ICD-10 a step forward or backwards? Inj Prev. 1999;5(4):247-53. [PMID: 10628910]

DOI:10.1136/ip.5.4.247

Submitted for publication August 10, 2009. Accepted in revised form March 8, 2010.

This article and any supplementary material should be cited as follows:

Carlson KF, Nugent SM, Grill J, Sayer NA. Accuracy of external cause-of-injury coding in VA polytrauma patient discharge records. J Rehabil Res Dev. 2010;47(8):689-98. DOI: 10.1682/JRRD.2009.08.0118

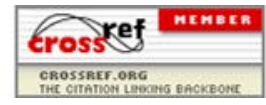


